\title{
Social Media in Food and Beverages Industry: Case of Klang Valley, Malaysia
}

\author{
Ilangovan Perumal ${ }^{1}$, Uma Devi Krisnan ${ }^{1} \&$ Nur Syahirah Binti Abdul Halim ${ }^{1}$ \\ ${ }^{1}$ Faculty of Business, Accounting and Management, SEGi University, Kota Damansara, Malaysia \\ Correspondence: Ilangovan Perumal, Faculty of Business, Accounting and Management, SEGi University, Kota \\ Damansara, Malaysia. E-mail: ilangovan@segi.edu.my
}

Received: January 18, 2017

Accepted: April 15, $2017 \quad$ Online Published: May 17, 2017

doi:10.5539/ijbm.v12n6p121

URL: https://doi.org/10.5539/ijbm.v12n6p121

\begin{abstract}
Social media marketing plays an important role for the food and beverages industry either new or existing companies. The main objective of this study is to determine the factors influencing the usage of social media as a marketing medium in the food and beverage industry. The study was conducted to test the research question and hypotheses. Data was gathered from quantitative research methods. This research investigate the factors influencing the usage of social media as a marketing media in the food and beverage industry. A total of 198 respondents were participated in this research. Questionnaire has been used to collect the information from respondents to measurement and quantify the respondent's response with the help of 5 point Likert scale (which indicate $1=$ strongly disagree, to $5=$ strongly agree). Data collected was analyzed using Pearson Correlation Coefficient and Multiple Regression Analysis. Result shows two of the independent variables; brand awareness and customer acquisition and retention have positive significant value and strong relationship with the dependent variable, the other two independent variables; information platform and feedback have negative significant value relationship with the dependent variable.
\end{abstract}

Keywords: social media, food and beverage, information platform, feedback, Malaysia

\section{Introduction}

Social media is a new media channel for marketers to advertise their products and services (Neti, 2011). Recently, it has become a part of marketing medium for organizations. Accompany with the advanced technology, many organizations rely on social media to reach out directly to existing consumers or to attract new ones. In marketing, social media has become a better marketing medium than traditional marketing which has shifted the ways in which consumers evaluate, choose and also share information (Patino, Pitta, \& Quinones, 2012). Social media such as Facebook, Twitter, Instagram and YouTube are often used by many organizations.

Consequently, it is no wonder that consumers will be able to get information at a very fast pace and only at their fingertips since technology always has had a huge impact on marketing (Halji, 2014). Researcher identified that the industry's top performing companies have an integrated and active social media presence (Snyder, 2013). Nowadays, this has resulted in an interesting choice of food within the society. Thus, F\&B industry are finding new ways to engage their customers through social media. Researcher stated that, the use social media in this advanced-era whereby mostly generation $Y$ is dominating consumer in F\&B industry (Hajli, 2014).

Accordingly, researcher identified that influences of social media allowing many F\&B companies to leverage on multiple media touch points in aiming to build up their brands (Poon, 2014). Advanced technology is providing the F\&B companies opportunities to explore new ways to have better understanding in customer acquisition and retention (Dolan, 2013). The importance of using the social media in the F\&B industry is highly relevant in Malaysia. There are many social media tools available and the choice of which ones to use can be overwhelming (Parker, 2011). F\&B companies on using social media as an information platform where Malaysian consumers will have access to variety of sources for information (Saaid, 2013).

Besides that, researchers identified that $\mathrm{F} \& \mathrm{~B}$ companies using social media to gathered consumers' feedback to improving their business (Saaid, 2013; Snyder, 2013). F\&B companies will be able to gain competitive advantages by using social media as marketing medium. In recent years, it is a trend of using social media as the result of advanced technology by the current generations. The current generations spend most of their time using 
the social media to "connect with the world" (Schiffman, Kanuk, \& Wisenblit, 2010).

Successively, this research desires to identify the factors that affecting the social media implementation in food and beverages industry in Malaysia. This research aims to identify the relationship between consumers' perception towards the usage of social media as a marketing media in food and beverages industry. The rest of the paper is organized as follows: first discussion of the relevant literature is presented; then the methodology is discussed; findings presented; and finally the paper concludes with a discussion of academic implications and area for future research.

\section{Literature Review}

Recent developments in communication and information technologies have led to radical changes world-wide. Henceforth, usage of social media in food and beverages industry intensely has increasing. Social media can be defined as a platform where people will be able to connect and share information with each other (Evans, 2012). Therefore, this allowed the organizations to obtain the detailed consumer information which was not able to access in the past (Sawchuk, 2011).

Hereafter, social media usage has increased the need for organizations especially, to open up their own page in Facebook, YouTube and other such sites in aiming to build communities around them (Baron, Conway, \& Warnaby, 2010). This study will focuses on four issues which are considered to be fairly important factors that could influence the usage of social media as marketing medium in the F\&B industry. The factors are: build brand awareness; information platform; feedback; and customer acquisition and retention. These are the four factors that will be discussed in this research.

\subsection{Brand Awareness and Social Media}

In any companies, brands are one of the most important intangible assets which contribute to greater value and market success. In recent years, traditional marketing does not work like how it used to be anymore especially in the F\&B industry as mentioned before, due to the advancement of technology and internet applications. Furthermore, the usage of social media among companies and also the public is growing rapidly.

According to Burson-Marsteller Asia Pacific Report (2011), many Malaysian (general) companies are using social media for corporate communications and marketing activities. Thus, Malaysian companies especially those in Klang Valley have realized the need to have the social media presence for their companies. The social media will need to be used effectively by the companies. The F\&B companies are building and maintaining their social media public pages in order to build brand awareness and to improve their social network with their customers (Parveen, Jaafar, \& Ainin, 2014).

H1: There is a significant relationship between brand awareness and social media as marketing medium in the $\mathrm{F} \& \mathrm{~B}$ industry.

\subsection{Information Platform and Social Media}

Information is defined as the set of facts obtained from data structures when someone interprets and attaches narrative meaning to the data sources. Social media is the platform that assists the progress of getting information sharing and participation from users of the media in order to create and distribute the content (Steenkamp \& Hyde-Clarke, 2014). In this era, the F\&B companies should consider using the social media especially when it comes to giving out information about their business and also any information regarding their products or services.

The advantage of using social media is that it is relatively low cost (but the companies will still have to use it effectively in order for it to be a success) and it enables the companies to connect their business to end-consumers directly by facilitating various areas of marketing such as advertisings, promotions and marketing communications (Kaplan \& Haenlein, 2010).

$\mathrm{H} 2$ : There is a significant relationship between information platform and social media as marketing medium in the F\&B industry.

\subsection{Feedback and Social Media}

Feedback in this case can be defined as the information provided by the customers regarding the aspects of the company's performance or understanding. It may be among the most effective means of establishing what the customer regards as a satisfactory level of performance and if dissatisfactions exist within the operation as it is based on the actual performance rather than false situations (Egan, 2011).

Thus, the F\&B executives recognized the significant impact that social, digital and mobile technologies have on 
business growth. In addition to that, companies that uses social media not only to build local communities, but also to collect customers' feedback which will lead to promoting new product ideas (Snyder, 2013).

H3: There is a significant relationship between gaining feedback from customers and social media as marketing medium in the F\&B industry.

\subsection{Customer Acquisition and Retention and Social Media}

Customer acquisition is known as a marketing activity to form relationships with new customers while acquisition costs and targeting high value customers (Chaffey \& Chadwick, 2012). The focus on customer acquisition will sometimes push the companies to not only change their marketing plans, but also their product, service, price and placement strategies (Kotler, Armstrong, Harris, \& Piercy, 2013). The F\&B companies in Klang Valley use this social media sites to acquire and increase the customer retention as it is important for them to increase their business level in terms of profit and also market share.

Social media could provide customers with an alternative support channel as well as enhanced service and value. It was decided that social media should be integral to the business, ensuring that customers were always dealt with efficiently and treated empathetically. Being seen to do this would ensure that the brand's reputation was well thought of by customers, who it was hope would, in turn recommend the company and their products (Holloman, 2013).

H4: There is a significant relationship between customer acquisition and retention and social media as marketing medium in the F\&B industry.

\section{Methodology}

The targeted population of this study were Malaysian citizens living in Klang Valley. The citizens are the most important aspect of knowing if what the $\mathrm{F} \& \mathrm{~B}$ companies do as their social media campaign reaches out to those target audiences. The survey is being conducted in the Klang Valley area. There are many F\&B companies in this area which lead to many citizens using the social media to connect with those companies. Therefore, the choices of those citizens as the respondents are qualified in answering the questionnaire (Sekaran, 2003). This research uses social media (1 independent variable) x 4 factors (brand awareness, information platform, feedback, and customer acquisition). Researcher defined purposive sampling as a type of sampling in which, tries to make the sample representative, depending on research purpose, thus being the representation subjective (Teddlie, \& Yu, 2007). Researcher uses the purposive sampling techniques in this research (Hair, Bush, \& Ortinau, 2006). Therefore, this study obtained 198 respondents, whom were selected from Klang Valley, Malaysia. The questionnaire were presented in English language. The questionnaire has two sections: the first was for demographic; the second covered five propositions which is brand awareness, information platform, feedback, and customer acquisition. The questionnaires chosen for this research used Likert scale questionnaires (Jackson, 2012). The five anchors used in this interval scale are strongly disagree (1) to strongly agree (5). Data was analyzed using Pearson Correlation and Multiple Regression Analysis.

\section{Findings}

The respondents profile is summarized in Table 1. The findings score for variables was tested by all the factors is depicted below. Pearson correlation analysis is presented in Table 2 and multiple linear regression in Table 3.

Table 1. Respondent's profile

\begin{tabular}{|c|c|c|c|}
\hline Variable & & Frequency & Percentage \\
\hline \multirow[t]{2}{*}{ Gender } & Male & 83 & 41.9 \\
\hline & Female & 115 & 58.1 \\
\hline \multirow[t]{5}{*}{ Age } & 19 years old and below & 16 & 8.1 \\
\hline & $20-24$ years old & 105 & 53.0 \\
\hline & $25-29$ years old & 56 & 28.3 \\
\hline & $30-34$ years old & 13 & 6.6 \\
\hline & 35 years old and above & 8 & 5.0 \\
\hline \multirow[t]{5}{*}{ Highest Education Level } & Secondary education & 11 & 5.6 \\
\hline & STPM/Pre U & 30 & 15.2 \\
\hline & Diploma & 27 & 13.6 \\
\hline & Degree & 120 & 60.6 \\
\hline & Others & 10 & 5.0 \\
\hline
\end{tabular}


Female respondents are highest compared to the male respondents with $58.1 \%$ and $41.9 \%$ respectively. Also, this shows that female uses the social media more than the male respondents.

Age range between $20-24$ years old at $53 \%$. This means that the age group of $20-24$ years old uses social media a lot more than the other age groups. The highest education level of the respondents is Bachelor Degree at the percentage of $60.6 \%$ with 120 respondents.

Table 2. Pearson correlation analysis

\begin{tabular}{|c|c|c|c|c|c|c|c|}
\hline \multicolumn{3}{|l|}{ Variable } & \multirow{2}{*}{$\begin{array}{l}\text { Social } \\
\text { Media }\end{array}$} & \multirow{2}{*}{$\begin{array}{l}\text { Brand } \\
\text { Awareness }\end{array}$} & \multirow{2}{*}{$\begin{array}{l}\text { Information } \\
\text { Platform } \\
0.489^{* *}\end{array}$} & \multirow{2}{*}{$\begin{array}{l}\text { Feedback } \\
0.432 * *\end{array}$} & \multirow{2}{*}{$\begin{array}{l}\text { Customer } \\
\text { Acquisition }\end{array}$} \\
\hline Social Media & & Pearson Correlation & & & & & \\
\hline & & Sig (2-tailed) & & 0.000 & 0.000 & 0.000 & 0.000 \\
\hline Brand & & Pearson Correlation & $0.572 * *$ & 1 & $0.478 * *$ & $0.414 * *$ & $0.436^{* *}$ \\
\hline Awareness & & Sig (2-tailed) & 0.000 & & 0.000 & 0.000 & 0.000 \\
\hline Information & & Pearson Correlation & $0.489 * *$ & $0.478 * *$ & 1 & $0.512 * *$ & $0.564 * *$ \\
\hline Platform & & Sig (2-tailed) & 0.000 & 0.000 & & 0.000 & 0.000 \\
\hline \multirow[t]{2}{*}{ Feedback } & & Pearson Correlation & $0.432 * *$ & $0.414 * *$ & $0.512 * *$ & 1 & $0.495 * *$ \\
\hline & & Sig (2-tailed) & 0.000 & 0.000 & 0.000 & & 0.000 \\
\hline Customer & & Pearson Correlation & $0.669^{* *}$ & $0.436^{* *}$ & $0.564 * *$ & $0.495 * *$ & 1 \\
\hline Acquisition & $\&$ & Sig (2-tailed) & 0.000 & 0.000 & 0.000 & 0.000 & \\
\hline Retention & & & & & & & \\
\hline
\end{tabular}

**. Correlation is significant at the 0.01 level (2-tailed).

There is a strong positive relationship between social media and brand awareness with 0.572 and significant value of 0.000 . Subsequently, there is a strong relationship between social media and information platform with 0.489 and significant value of 0.000 . Pearson correlations of 0.432 , there is a relationship between social media and feedback with the significant value of 0.000 . There is a strong positive relationship between social media as marketing medium and customer acquisition and retention (0.669) and significant value of 0.000 . The results showed that all of the independent variables have a strong positive relationship with the dependent variable which is the social media.

Table 3. Multiple linear regression

\begin{tabular}{lll}
\hline Variables & Beta & Sig. \\
\hline Brand Awareness & 0.315 & 0.000 \\
Information Platform & 0.041 & 0.517 \\
Feedback & 0.040 & 0.549 \\
Customer Acquisition \& Retention & 0.489 & 0.000 \\
R & & \\
R square & $0.739^{\mathrm{a}}$ & \\
Adjusted R square & 0.546 & \\
Significant & 0.537 & \\
F-value & $0.000^{\mathrm{b}}$ & \\
\hline
\end{tabular}

a. Dependent Variable: Social Media.

b. b. Predictors: (Constant), Customer Acquisition \& Retention, Brand Awareness, Feedback, Information Platform.

The $\mathrm{R}$ square indicates that $73.9 \%$ of the total variance in the dependent variables (social media) is explained by the total independent variables (brand awareness, information platform, feedback, and customer acquisition and retention). The arrangement of strengths among the independent variables (brand awareness, information platform, feedback, and customer acquisition and retention) that contributes to the dependent variable (social media) are brand awareness $(B=0.315)$, information platform $(B=0.041)$, feedback $(B=0.040)$, and customer acquisition and retention $(\mathrm{B}=-0.489)$. Therefore, the results of hypotheses was presented below: 


\subsection{Hypothesis Results}

H1: There is a significant relationship between brand awareness and social media in the F\&B industry.
H2: There is a significant relationship between information platform and social media in the F\&B industry.
H3: There is a significant relationship between gaining feedback from customers and social media in the F\&B industry.
H4: Thejected

\section{Discussion}

Therefore, the research findings assumed and concluded that the Pearson correlation analysis had come to a varied result on positive significant and strong relationships towards the brand awareness, information platform, feedback, and customer acquisition.

Based on the results discussed, the independent variables have diverse significant levels to the dependent variable which is the social media as marketing medium. In multiple regression analysis, two of the independent variables; brand awareness and customer acquisition and retention have positive significant value and strong relationship with the dependent variable. Therefore, the hypotheses are supported. However, the other two independent variables; information platform and feedback have negative significant value relationship with the dependent variable. Thus, the hypotheses are not supported. The relationship levels are shown on the compared analysis table below:

The correlation of the independent variable which indicates significant and positive relationship with the usage of social media as marketing medium. This means that the independent variables (brand awareness, information platform, feedback and customer acquisition and retention) are acceptable and influenced the usage of social media as marketing medium in the food and beverage industry. All of the independent variables stated above are important in order to measure the performance of the food and beverage companies.

Brand awareness often taken for granted but actually is can be the key to successful companies as brand awareness can provide competitive advantages to the companies (Aaker \& McLoughlin, 2010). Brand awareness is crucial in every F\&B companies in Malaysia especially in Klang Valley area where there are many F\&B companies available to the customers. Whether the company is new or an existing company, brand awareness plays an important part of their business since there are high rate of competitors around Klang Valley area. By using social media, the F\&B companies will be able to build brand awareness in short amount of time and also less cost, especially through word-of-mouth. Therefore, the positive relationship between brand awareness and the usage of social media as marketing medium in the F\&B industry is the evidence that the F\&B companies should not take lightly about brand awareness.

Information platform is important in every $\mathrm{F} \& \mathrm{~B}$ companies to connect with existing or new customers. Social media is a place where people are able to share information with each other which is one of the reasons why F\&B companies should always update their social media sites with the latest information. As for the correlation analysis, there is a positive relationship between information platform and social media as marketing medium.

Feedback in this case can be defined as the information provided by the customers regarding the aspects of the company's performance or understanding (Hattie \& Timperley, 2007). Feedback is known to be the most powerful influences on learning and achievement. However, the impact of feedback can be either positive or negative. By using social media, it enables companies to extend their brand image and also immediately respond to customer inquiries and comments which are highly anticipate by the customers. For the correlation analysis, there is a positive relationship between feedback and social media as marketing medium

Lastly, customer acquisition and retention has a positive relationship with social media as marketing medium for correlation analysis. Gaining new customers and retaining the existing customers can be quite difficult for every F\&B companies. Thus, by maintaining good marketing strategies, F\&B companies will be able to have the competitive advantage. The positive relationship makes the hypotheses to be accepted.

\subsection{Implication of the Study}

This research is about the discussion of factors influencing the usage of social media in the food and beverage industry in Klang Valley. Based on the results obtained and discussed, researcher understand that brand awareness, information platform, feedback, customer acquisition and retention are strongly influencing the usage of social media in the F\&B industry.

\subsection{Future Research}

For the future research, the researcher may use the other factors that influence the usage of social media as 
marketing medium in F\&B industry such as pricing, and strategies. The future researcher should reconsider the same feedback and information platform questionnaire statements as the statements are not well acceptable by the respondents. Thus, the future research should implement on qualitative research method to collect more accurate and reliable information.

\section{References}

Aaker, D. A., \& McLoughlin, D. (2010). Strategic Market Management: Global Perspectives. United Kingdom: John Wiley \& Sons.

Baron, S., Conway, T., \& Warnaby, G. (2010). Relationship Marketing: A Customer Experience Approach. London: Sage.

Burson-Marsteller Asia Pacific Report. (2011). Generation Y, Social Networks \& the F\&B Industry: Case Study: Food service $\quad$ Brandon Facebook. $\quad$ Retrieved from http://www.campaignbrief.com/BM_AP_SocialMedia_Infographics_Booklet_H12011.pdf

Chaffey, D., \& Chadwick, E. F. (2012). Digital Marketing 5th ed. Harlow: Pearson.

Dolan, P. (2013). 2013 Food and Beverage Industry Outlook Survey. United States: KPMG.

Egan, J. (2011). Relationship Marketing: Exploring relational strategies in marketing. Harlow: Prentice Hall.

Evans, D. (2012). Social Media Marketing: An Hour a Day (2nd ed.). Indiana: John Wiley \& Sons, Inc.

Hair, J. F., Bush, R. P., \& Ortinau, D. J. (2006). Marketing Research. New York: McGraw-Hill Irwin.

Hajli, M. N. (2014). A study of the impact of social media on consumers. International Journal of Market Research, 56(3) 387-404. https://dx.doi.org/10.2501/IJMR-2014-025

Hattie, J., \& Timperley, H. (2007). The Power of Feedback. Review of Educational Research, 77(1), 81-112.

Holloman, C. (2013). The Social Media MBA In Practice. United Kingdom: Wiley.

Jackson (2012). Research Methods and Statistics: A Critical Thinking Approach - Fourth Edition. Cengage Learning.

Kaplan, A. M., \& Haenlein, M. (2010). Users of the World, Unite! The challenges and opportunities of Social Media. Business Horizons, 53(1), 59-68.

Kotler, P., Armstrong, G., Harris, L., \& Piercy, N. (2013). Principles of Marketing - European edition. London: Pearson.

Neti, S. (2011). Social Media and Its Role in Marketing. International Journal of Enterprise Computing and Business Systems, Vol. 1(2) 1- 16 (ISSN Online: 2230-8849). Retrieved from http://www.ijecbs.com/July2011/13.pdf

Parker, C. (2011). 301 Ways to Use Social Media to Boost Your Marketing. United States: McGraw-Hill .

Parveen, F., Jaafar, N. I., \& Ainin, S. (2014). Social Media Usage and Organizational Performance: Reflections of Malaysian Social Media Managers. Telematics and Informations, 32, 67-78.

Patino, A., Pitta, D. A., \& Quinones, R. (2012). Social Media's Emerging Importance in Market Research. Journal of Consumer Marketing, 29(3), 233-237.

Poon, S. T. (2014). Designers' Role in Marketing Lifestyle Brands to the Shopping Culture Generation. International Conference on Innovation Challenges in Multidisciplinary Research \& Practice. 1, 71-88. Malaysia: Global Illuminators.

Saaid, M. H. (2013). Consumerism Trend in Malaysia. Kuala Lumpur: Malaysian Industry-Government Group for High Technology (MIGHT).

Sawchuk, D. (2011). The Changing Landscape of Online Qualitative Research. Alert, 51(3), 20-24.

Schiffman, L. G., Kanuk, L. L., \& Wisenblit, J. (2010). Consumer Behavior. New Jersey: Pearson.

Sekaran, U. (2003). Research Methods for Business. New Jersey: John Wiley \& Sons.

Snyder, D. (2013). Social Media in the Food and Beverage Industry. Green Hasson Janks \& Food Digest, 1-3.

Steenkamp, M., \& Hyde-Clarke, N. (2014). The Use of Facebook for Political Commentary in South Africa. Telematics Information, 31(1), 91-97. https://dx.doi.org/10.1016/j.tele.2012.10.002

Teddlie, C., \& Yu, Fen. (2007). Mixed Methods Sampling: A Topology With Examples. Journal of Mixed 
Methods Research, 1, 77-100. https://dx.doi.org/10.1177/2345678906292430

\section{Copyrights}

Copyright for this article is retained by the author(s), with first publication rights granted to the journal.

This is an open-access article distributed under the terms and conditions of the Creative Commons Attribution license (http://creativecommons.org/licenses/by/4.0/). 